Research Article

\title{
Study of the Press Fit Bearing-Shaft Joint Dimensional Parameters by Analytical and Numerical Approach
}

\author{
Zuzana Murčinková (D, Petr Baron, and Martin Pollák (iD \\ Faculty of Manufacturing Technologies with a Seat in Presov, Technical University of Košice, Košice, Slovakia \\ Correspondence should be addressed to Martin Pollák; martin.pollak@tuke.sk
}

Received 13 February 2018; Revised 5 April 2018; Accepted 11 April 2018; Published 10 May 2018

Academic Editor: Aniello Riccio

Copyright ( 2018 Zuzana Murčinková et al. This is an open access article distributed under the Creative Commons Attribution License, which permits unrestricted use, distribution, and reproduction in any medium, provided the original work is properly cited.

\begin{abstract}
The study of press fit bearing-shaft joint dimensional parameters by means of analytical and numerical calculations in order to identify those parameters of the press fit joints which significantly influence the life of the bearings fitted by pressing is dealt in this paper. The mounting and conditions of fit joint are the significant factors affecting the operability and life of the bearings and consequently that of rotating machines and the whole technical units. The aim of the analysis and study is to determine the tangential and radial stress, the radial displacement, and the influence of the shape features and the size of the interference on the change of the radii in the press fit bearing-shaft joint, in particular, the ball bearings of 6014 2RSR C3 type. Moreover, on the basis of obtained results, the paper discusses the impact of shaft dimensional and geometrical accuracy on the bearing lifetime.
\end{abstract}

\section{Introduction}

The rolling bearing itself is the multiparameter system, and its lifetime is influenced by many parameters. Rolling bearings represent reliable parts of long-life machines, provided they are properly mounted and maintained. Reliable operation of rolling bearings does not lie exclusively in the quality of the bearings themselves. The life of a rolling bearing is influenced by other factors too. These are mainly the operating environment, professional installation, and proper maintenance. The real operating conditions of bearings may strongly change the theoretically estimated bearing life. The well-known equation of bearing life $L$ calculation is in the form

$$
L=a\left(\frac{C}{F}\right)^{p}
$$

where $a$ is the coefficient in range $0.1 \div 10$ according to experiences and measurements depending on special bearing properties and operating conditions; $C$ is the base dynamic load rating (in catalogues), it means the load that responds to basic bearing life of million revolutions; $F$ is the applied load (the load $F$ is substituted by $F_{e}$-equivalent dynamic load); and $p$ is the exponent that is chosen in accordance with the outcomes of experiments ( $p=3$ for ball bearings, and $p=10 / 3$ for roller bearings).

It should be noticed that the range of coefficient $a$ is very wide. The signs of bearing failure can appear in several years, months, also in a few days, or even a few hours of operation [1]. In order to take advantage of the bearing's life potential inside the machine, it is necessary to observe relatively strict requirements for mounting, lubrication, clearance, bearing setting, and other such requirements. If these requirements are met, the bearing is able to work for a long period of time.

The issues of the bearing housing and joint are among the most important factors that may cause subsequent bearing failures. The bearing properties are fully utilized only when the bearing rings are supported throughout the circumference and over the entire bearing race width. The fixed contact surface may be cylindrical or conical in shape; alternately, it may be planar in case of the axial bearings. The contact surfaces must be manufactured with adequate accuracy. Appropriate radial locking and adequate fit will only be achieved if the bearing-shaft joint involves interference [2]. However, there can be a requirement of simple assembling and dismantling or of enabling the axial displacement of the axial bearing. In these cases, it is not possible to choose press fit joint for the bearing rings. In cases where the transition fit 
is proposed, the steps to prevent the possible wear caused by ring sliding have to be made $[3,4]$.

\section{Literature Review}

At present, the analytical and numerical methods are available to design or analyze the fit joint. In the field of press fit joints, the analytical solution was used by Lippmann to indicate that contact pressure varies with temperature. He said that the increase in temperature leads to a decrease in yield stress, correcting which causes deformation of the plastic material, thereby reducing the load capacity of the joint [5].

The analytical techniques used to design press fit on Lame's equations are based on two-dimensional stress analysis in the elastic range. Lame's solution is limited by its simplistic assumptions. Zhang et al. analyzed a press fit joint between a stepped shaft and ring gear using both analytical and numerical methods and concluded that Lame's equations underestimate the contact pressure by up to $78 \%$ [6]. The analytical models have been used to study the contact pressure and stress distribution in press fit joints, the effect of surface roughness, and thermal cycles. Yang et al. highlight the importance of surface roughness in the press fit joint and demonstrate experimentally that the extraction load fluctuates up to $300 \%$ for Ra values of $0.24-6.82 \mu \mathrm{m}$ [7]. Wang compared the performance of lugs under various clearance and interference values, and he concluded that the use of a carefully adjusted press fit increases the durability of the joint [8]. Croccolo et al. developed an analytical model to determine the contact pressure between two different materials and said that if the stiffness of both parts is close, the actual interference will probably be less than the estimated interference [9]. Mori et al. give a broad overview concerning the connection process, including the connection to ensure the overlap of the press connection. For ring-tube joining by expansion, the authors point out that the optimal forming pressure is achieved before deformation of the ring that begins to deform plastically. At the same time, they suggest that any further increase in the forming pressure results in a negligible increase in the interference pressure and joint strength. The strength of the joint can be increased by increasing the surface roughness or by cleaning the contact surfaces [10]. Zhang et al. have studied the stress distribution at the interface of a ball bearing, in particular, on the edges with the finite element method. They established a strength criterion based on two safety factors $\lambda_{\mathrm{s}}$ (factor of safety to ensure component strength) and $\lambda_{\mathrm{p}}$ (factor of safety to ensure no slippage on mating surfaces). Boutoutaou et al. used finite elements modeling to design a tool for forging shrunk parts to ensure the final dimensions of the finished product [11]. Some recent studies show the advantage of higher resolution models to understand interference-fit joints better.

In this paper, we analyze and demonstrate the importance of press fit joint dimensional parameters, and thus, we quantify the importance of individual parameters based on both the analytical and numerical approach. The study of press fit joint is applied on the joint of the ball rolling bearing and the shaft because the accuracy of bearing production is in the micrometer order, but in most cases, the mounting of bearing is done by users of shafts that can be manufactured

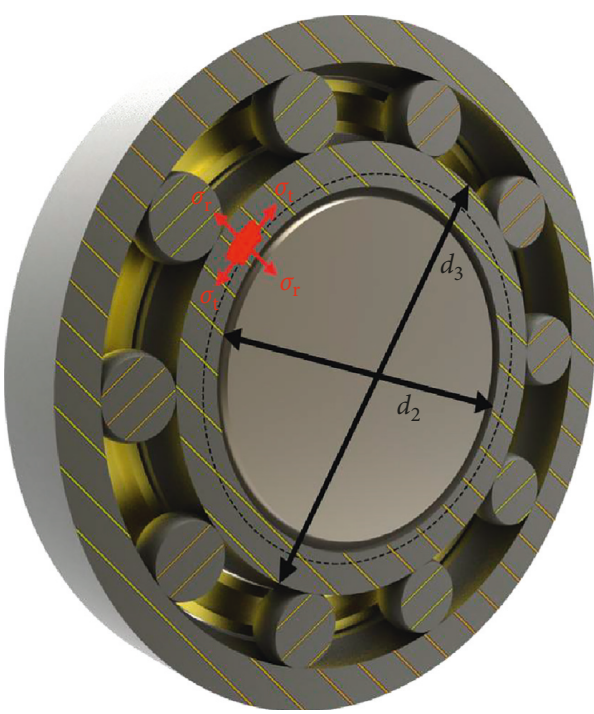

FIgURE 1: Radial and tangential stress occurring in the press fit bearing-shaft joint.

in different accuracies, both dimensional and geometrical. Both our analytical and numerical models analyze the dimensional parameters in the elastic range, without taking into account the roughness of contact surfaces and temperature changes caused by the operating state.

\section{Press Fit Joint and Its Parameters}

The press fit (also called interference or force fit) joint is defined as a fixed, nondismountable joint. There are some authors who defined the press fit joint as very difficult to dismount. The mounting of this joint is based on the elastic deformations in the contact surfaces that are pressed together [12]. The contact surfaces are mostly cylindrical in shape, but they can also be slightly conical. The press fit joints do not require the use of shaft keys as feathers or tappers and slots which would otherwise reduce the strength of the joint. Through this, the press fit joints can be smaller.

In order to obtain a press fit joint, the following condition must be met: the mounting diameter of the inner component must be larger than the mounting diameter of the outer component. Such a difference is called interference. This results in the already mentioned elastic deformation which causes stress in the components. The stress state can be considered as plane stress (stress generated in the axial direction may be neglected). A tangential stress is generated in the tangent direction $\sigma_{\mathrm{t}}$, and a radial stress $\sigma_{\mathrm{r}}$ is generated in the radial direction (Figure 1) [13, 14].

The radial and tangential stress as well as the contact pressure can be calculated analytically according to the thick-walled pressure cylinders theory. The tangential stress $\sigma_{\mathrm{t}}$ and the radial stress $\sigma_{\mathrm{r}}$ are given by

$$
\sigma_{\mathrm{t}, \mathrm{r}}(r)=A \pm \frac{B}{r^{2}}
$$

where $A$ and $B$ are the integration constants determined by boundary conditions and $r$ is the radius. Contact pressure $p_{2}$, which occurs after the shaft I and the hub II, is pressed: 


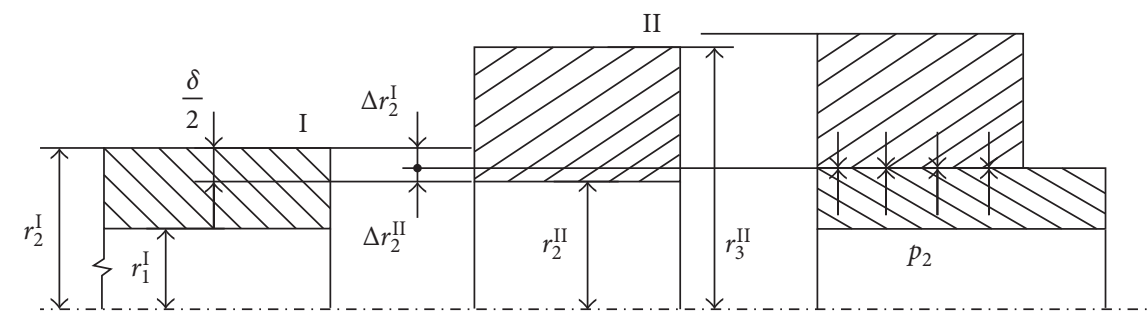

FIgURE 2: Interference in press fit joint.

$$
p_{2}=\frac{\delta E}{2 r_{2}} \frac{\left(r_{3}^{2}-r_{2}^{2}\right)}{2 r_{3}^{2}}
$$

where $\delta$ is the interference, $E$ is Young's modulus of elasticity, $r_{2} \cdot\left(d_{2} / 2\right)$ is the radius of shaft $\mathrm{I}$, and $r_{3} \cdot\left(d_{3} / 2\right)$ is the outer radius of hub II (Figures 1 and 2).

The interference $\delta$ is equal to the difference in the outer diameter of the inner ring-hollow shaft and the inner diameter of the outer ring-hub (Figure 2). After pressing, the $r_{2}^{\mathrm{I}}$ radius reduction occurs by $\Delta r_{2}^{\mathrm{I}}$ value of the inner ring (hollow shaft) and the outer ring II (hub) on $r_{2}^{\mathrm{II}}$ the radius increases by the $\Delta r_{2}^{\mathrm{II}}$ value.

$$
\left|\Delta r_{2}^{\mathrm{I}}\right|+\Delta r_{2}^{\mathrm{II}}=\frac{\delta}{2}
$$

Radial shaft displacement $\Delta r_{2}^{\mathrm{I}}$ (decrease of the original shaft radius-compression):

$$
\Delta r_{2}^{\mathrm{I}}=\frac{p_{2} r_{2}}{E}(1-\mu)
$$

where $\mu$ is Poisson's ratio.

Radial hub displacement $\Delta r_{2}^{\mathrm{II}}$ (increase of the original shaft radius-expansion):

$$
\Delta r_{2}^{\mathrm{II}}=\frac{p_{2} r_{2}}{E}\left(\frac{r_{2}^{2}+r_{3}^{2}}{r_{3}^{2}-r_{2}^{2}}+\mu\right) .
$$

The load bearing capacity between the pressed hub and the shaft is mainly due to the size of the interference, and it is determined by

(i) the wall thickness of the outer component,

(ii) the type of material used for both connected components,

(iii) temperature of the components during mounting and also their operating temperature,

(iv) elastic deformation induced by pressing,

(v) joint length,

(vi) surface quality of contact surfaces and so on.

\section{Analytical Solution and Numerical Experiment}

Based on our partner's request, we have calculated a press fit joint of shaft (solid and hollow) with 6014 2RSR C3 ball bearing. The results of the analytical calculation were verified by computer simulation in the environment of the PTC Creo system, using the FEM method-finite element method (p-version). The main aim of the calculations and analyses applied was to study the correlation of the analytical calculation of the stress of the press fit joint of the bearing with the shaft with the results of its numerical simulation and to analyze the changes of the shaft radii and of the inner ring of the bearing under the influence of the interference.

The calculation was made for

(i) radial stress

(ii) tangential stress

(iii) reduction of the radial shaft displacement

(iv) increase of the radial hub displacement

4.1. The Analytical Calculation of the Press Fit Joint of the Shaft and the Bearing. Analysis input values (see Figure 2):

(i) Interference fit in a single-hole system: $\varphi 70 \mathrm{H} 7 / \mathrm{p} 6$

(ii) Limit deviations: $\varphi 70 \mathrm{H} 7\left(\begin{array}{c}+0.030 \\ 0\end{array}\right), \varphi 70 \mathrm{p} 6\left(\begin{array}{l}+0.051 \\ +0.032\end{array}\right)$

(iii) Material: steel $\mu=0.3, E=2.10^{5} \mathrm{MPa}$

(iv) Solid shaft: $r_{1}^{\mathrm{I}}=0 \mathrm{~mm}, r_{2}^{\mathrm{I}}=35 \mathrm{~mm}$

(v) Hollow shaft: $r_{1}^{\mathrm{I}}=20 \mathrm{~mm}, r_{2}^{\mathrm{I}}=35 \mathrm{~mm}$

(vi) Hub: $r_{2}^{\mathrm{II}}=35 \mathrm{~mm}, r_{2}^{\mathrm{II}}=41.4 \mathrm{~mm}$

(radius determined according to dimensions of the inner bearing ring, here without groove-shape feature)

4.1.1. Interference Calculation. Maximum interference: $\delta_{\max }=$ $d_{\max }-D_{\min }=0.051 \mathrm{~mm}-0=0.051 \mathrm{~mm}$.

Minimum interference: $\delta_{\min }=d_{\min }-D_{\max }=0.032 \mathrm{~mm}-$ $0.030 \mathrm{~mm}=0.002 \mathrm{~mm}$.

Maximum contact pressure according to (3) for $\delta_{\max }$ :

$$
p_{2}=20,785 \mathrm{MPa} \text {. }
$$

Maximum reduction of $\Delta r_{2}^{\mathrm{I}}$ shaft radius according to (5):

$$
\Delta r_{2}^{\mathrm{I}}=0.00255 \mathrm{~mm} \text {. }
$$

Maximum increase of $\Delta r_{2}^{\mathrm{II}}$ hub radius according to (6):

$$
\Delta r_{2}^{\mathrm{II}}=0.02295 \mathrm{~mm} \text {. }
$$

Then, interference $\delta$ is

$$
\begin{aligned}
\frac{\delta}{2}=\left|\Delta r_{2}^{\mathrm{I}}\right|+\Delta r_{2}^{\mathrm{II}} & =0.00255 \mathrm{~mm}+0.02295 \mathrm{~mm} \\
& =0.0255 \mathrm{~mm} \Rightarrow \delta=0.051 \mathrm{~mm} .
\end{aligned}
$$


4.1.2. Shaft Stress Calculation. Boundary conditions of the solid shaft:

$$
\begin{gathered}
\sigma_{r}^{\mathrm{I}}\left(r=r_{1}=0 \mathrm{~mm}\right)=-p_{2}, \\
\sigma_{r}^{\mathrm{I}}\left(r=r_{2}=35 \mathrm{~mm}\right)=-p_{2} .
\end{gathered}
$$

After substituting (11) according to (2), we get

$$
\begin{aligned}
& A^{\mathrm{I}}-\frac{B^{\mathrm{I}}}{r_{1}^{2}}=-p_{2}, \\
& A^{\mathrm{I}}-\frac{B^{\mathrm{I}}}{r_{2}^{2}}=-p_{2} .
\end{aligned}
$$

By solving the system of equations (12), we get integration constants $A^{\mathrm{I}}=-p_{2}$ and $B^{\mathrm{I}}=0$.

Then, according to (11), the tangential and radial stress on $r_{2}$ radius in a solid shaft has the same value:

$$
\begin{aligned}
\sigma_{t}^{\mathrm{I}}\left(r=r_{2}\right) & =\sigma_{t}^{\mathrm{I}}\left(r=r_{1}\right)=\sigma_{r}^{\mathrm{I}}\left(r=r_{1}\right)=\sigma_{r}^{\mathrm{I}}\left(r=r_{2}\right) \\
& =-p_{2}=-20,785 \mathrm{MPa} .
\end{aligned}
$$

Boundary conditions of the hollow shaft:

$$
\begin{aligned}
& \sigma_{r}^{\mathrm{I}}\left(r=r_{1}=20 \mathrm{~mm}\right)=0, \\
& \sigma_{r}^{\mathrm{I}}\left(r=r_{2}=35 \mathrm{~mm}\right)=-p_{2} .
\end{aligned}
$$

After substituting (14) in (2), we get

$$
\begin{aligned}
& A^{\mathrm{I}}-\frac{B^{\mathrm{I}}}{r_{1}^{2}}=0, \\
& A^{\mathrm{I}}-\frac{B^{\mathrm{I}}}{r_{2}^{2}}=-p_{2} .
\end{aligned}
$$

By solving the system of equations (15), we get the integration constants in the form

$$
\begin{gathered}
A^{\mathrm{I}}=-\frac{p_{2} \cdot r_{2}^{2}}{r_{2}^{2}-r_{1}^{2}}, \\
B^{\mathrm{I}}=-\frac{p_{2} \cdot r_{1}^{2} \cdot r_{2}^{2}}{r_{2}^{2}-r_{1}^{2}} .
\end{gathered}
$$

Then from (2), (16), and (17), the circumferential (tangential) stress in the hollow shaft $\sigma_{\mathrm{t}}^{\mathrm{I}}$ is

$$
\begin{aligned}
\sigma_{\mathrm{t}}^{\mathrm{I}}\left(r=r_{1}\right)=-\frac{2 \cdot p_{2} \cdot r_{2}^{2}}{r_{2}^{2}-r_{1}^{2}} & =-\frac{2 \cdot 20,785 \mathrm{MPa} \cdot 35^{2} \mathrm{~mm}^{2}}{\left(35^{2}-20^{2}\right) \mathrm{mm}^{2}} \\
& =-61,725 \mathrm{MPa}, \\
\sigma_{\mathrm{t}}^{\mathrm{I}}\left(r=r_{2}\right) & =-\frac{p_{2} \cdot\left(r_{2}^{2}+r_{1}^{2}\right)}{r_{2}^{2}-r_{1}^{2}} \\
& =-\frac{20,785 \mathrm{MPa} \cdot\left(35^{2}+20^{2}\right) \mathrm{mm}^{2}}{\left(35^{2}-20^{2}\right) \mathrm{mm}^{2}} \\
& =-40,940 \mathrm{MPa} .
\end{aligned}
$$

4.1.3. Hub Stress Calculation (Solid and Hollow Shaft). Boundary conditions of the hub:

$$
\begin{aligned}
& \sigma_{\mathrm{r}}^{\mathrm{II}}\left(r=r_{2}=35 \mathrm{~mm}\right)=-p_{2}, \\
& \sigma_{\mathrm{r}}^{\mathrm{II}}\left(r=r_{3}=41.4 \mathrm{~mm}\right)=0 .
\end{aligned}
$$

After completing (19 according to (2), we get

$$
\begin{aligned}
& A^{\mathrm{II}}-\frac{B^{\mathrm{II}}}{r_{2}^{2}}=-p_{2}, \\
& A^{\mathrm{II}}-\frac{B^{\mathrm{II}}}{r_{3}^{2}}=0 .
\end{aligned}
$$

By solving the system of equations (20), we get the integration constants in the form

$$
\begin{gathered}
A^{\mathrm{II}}=\frac{p_{2} \cdot r_{2}^{2}}{r_{3}^{2}-r_{2}^{2}}, \\
B^{\mathrm{II}}=\frac{p_{2} \cdot r_{3}^{2} \cdot r_{2}^{2}}{r_{3}^{2}-r_{2}^{2}} .
\end{gathered}
$$

Then from (2), (21), and (22), the circumferential (tangential) stress in the hub $\sigma_{t}^{\mathrm{II}}$ is

$$
\begin{aligned}
\sigma_{\mathrm{t}}^{\mathrm{II}}\left(r=r_{2}\right) & =\frac{p_{2} \cdot\left(r_{2}^{2}+r_{3}^{2}\right)}{r_{3}^{2}-r_{2}^{2}} \\
& =\frac{20,785 \mathrm{MPa} \cdot\left(35^{2}+41.4^{2}\right) \mathrm{mm}^{2}}{\left(41.4^{2}-35^{2}\right) \mathrm{mm}^{2}} \\
& =124,931 \mathrm{MPa}, \\
\sigma_{\mathrm{t}}^{\mathrm{II}}\left(r=r_{3}\right) & =\frac{2 \cdot p_{2} \cdot r_{2}^{2}}{r_{3}^{2}-r_{2}^{2}} \\
& =\frac{2 \cdot 20,785 \mathrm{MPa} \cdot 35^{2} \mathrm{~mm}^{2}}{\left(41.4^{2}-35^{2}\right) \mathrm{mm}^{2}}=104,146 \mathrm{MPa} .
\end{aligned}
$$

The final stress field is shown in Figure 3.

4.2. Numerical Simulation of Press Fit Joint. The analytically calculated stress and displacement of the analyzed press fit joint $(\varphi 70 \mathrm{H} 7 / \mathrm{p} 6)$ were verified by the $\mathrm{p}$-version of the finite element method (FEM) implemented in the Creo Simulate module of the PTC Creo parametric system. In this calculation, the mesh of finite elements does not change during the computing, and the required accuracy is achieved by increasing the polynomial order of the polynomial shape functions [15]. The maximum polynomial order obtainable in Creo Simulate is 9. This is the case of higher order approximation. These finite elements are designated as p-elements. They are characterized by greater shape diversity and a smaller number compared to h-elements. Some authors believe that using p-elements, even complex structures can be efficiently discretized with solid elements (threedimensional elements), even if the aspect ratio of the elements becomes very large. Moreover, p-version of FEM allows predicting the structural behavior of three-dimensional 

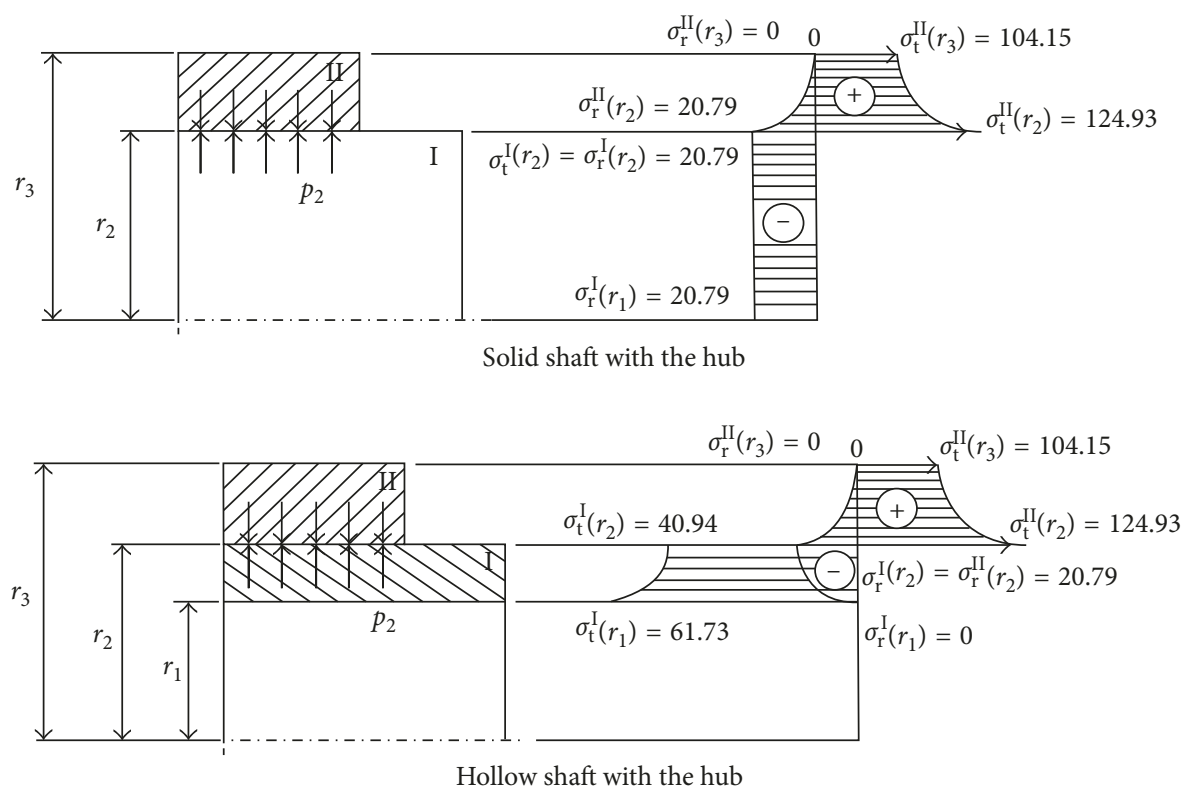

Figure 3: Stress in the solid and the hollow shaft with the hub (MPa).
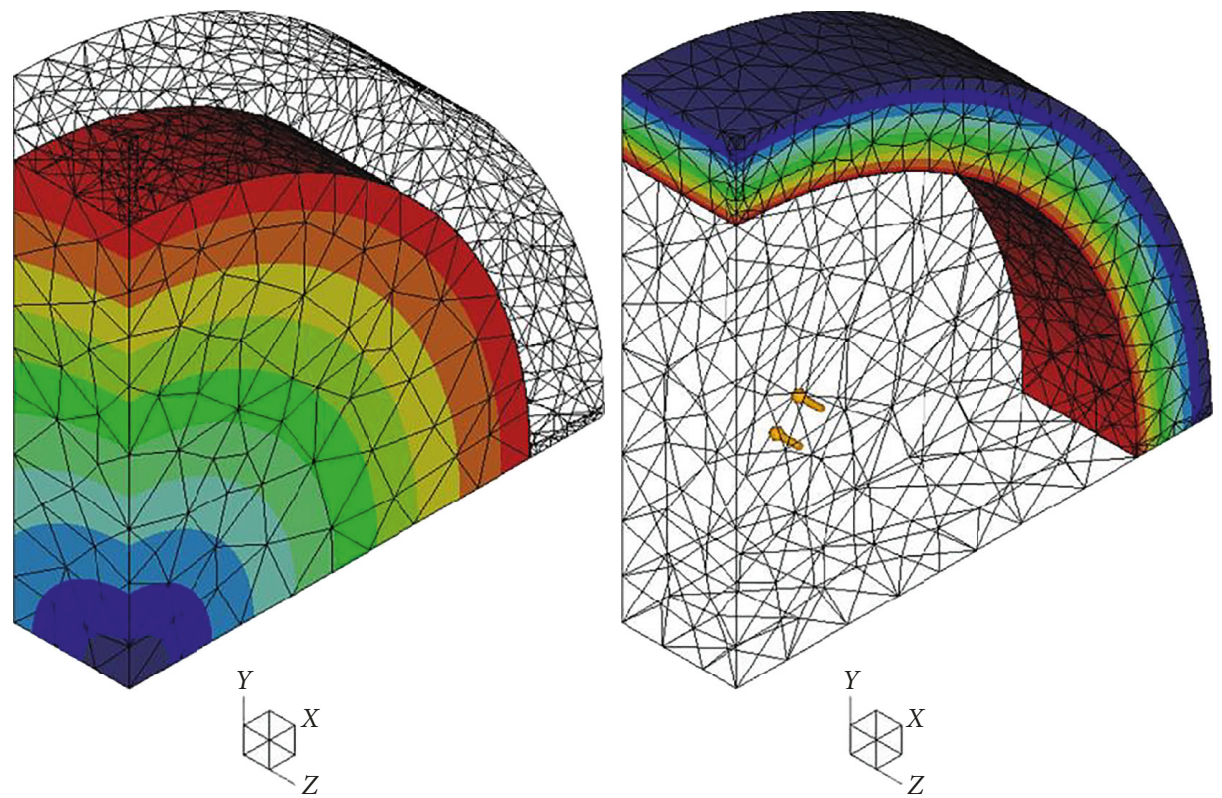

Figure 4: Displacement field (magnitude) of the shaft (left) and the hub with finite p-element mesh.

plates and shells with approximately the same amount of degrees of freedom as in the two-dimensional case, yet significantly more accurate due to the three-dimensional model [16].

The presented numerical model consists of $3741 \mathrm{p}$-finite elements-tetrahedrons (Figure 4). Maximum achieved polynomial order of shape functions is 5 , and the number of equations in last pass is 104,459 in this computation. The determined stress error of maximal principal stress is $0.1 \%$.

One-eighth of the press fit joint is modeled because of symmetrical boundary conditions. Interference fit is a type of model for nonlinear analysis with contact region in the contact surface. The computational method is the Newton-Raphson method. Five loading intervals and localized mesh refinement with convergence on contact forces are used for computation. Figure 4 shows magnitude of displacement fields having their maxima on the contact surfaces.

The following tables (Tables 1-3) show the comparison of the radial, tangential stress values, and the radial displacements in analytical and numerical calculations. The analytical and numerical solutions match very closely, ranging from $0.03 \%$ to $4.75 \%$ at the given finite element parameter setting. The model is reliable. 
TABLE 1: Radial stress comparison.

\begin{tabular}{lcccc}
\hline & Radius & $\begin{array}{c}\text { Analytical } \\
\text { calculation }\end{array}$ & $\begin{array}{c}\text { Numerical } \\
\text { calculation }\end{array}$ & Deviation (\%) \\
\hline \multirow{2}{*}{ Shaft $\sigma_{\mathrm{r}}^{\mathrm{I}}(\mathrm{MPa})$} & $r_{1}^{\mathrm{I}}$ & -20.785 & -20.981 & +0.94 \\
& $r_{2}^{\mathrm{I}}$ & -20.785 & -19.821 & -4.64 \\
\hline \multirow{2}{*}{ Hub $\sigma_{\mathrm{r}}^{\mathrm{II}}(\mathrm{MPa})$} & $r_{2}^{\mathrm{II}}$ & -20.785 & -20.791 & +0.03 \\
& $r_{3}^{\mathrm{II}}$ & 0 & -0.0055 & - \\
\hline
\end{tabular}

TABLE 2: Circumferential stress (tangential) comparison.

\begin{tabular}{ccccc}
\hline & Radius & $\begin{array}{c}\text { Analytical } \\
\text { calculation }\end{array}$ & $\begin{array}{c}\text { Numerical } \\
\text { calculation }\end{array}$ & Deviation (\%) \\
\hline \multirow{2}{*}{ Shaft $\sigma_{\mathrm{t}}^{\mathrm{I}}(\mathrm{MPa})$} & $r_{1}^{\mathrm{I}}$ & -20.785 & -20.834 & +0.24 \\
& $r_{2}^{\mathrm{I}}$ & -20.785 & -19.798 & -4.75 \\
\hline \multirow{2}{*}{$\mathrm{Hub} \sigma_{\mathrm{t}}^{\mathrm{II}}(\mathrm{MPa})$} & $r_{2}^{\mathrm{II}}$ & 124.931 & 124.341 & -0.47 \\
& $r_{3}^{\mathrm{II}}$ & 104.146 & 104.426 & +0.27 \\
\hline
\end{tabular}

TABLE 3: Radial displacements comparison.

\begin{tabular}{lccc}
\hline & $\begin{array}{c}\text { Analytical } \\
\text { calculation }\end{array}$ & $\begin{array}{c}\text { Numerical } \\
\text { calculation }\end{array}$ & Deviation (\%) \\
\hline Shaft $\Delta r_{2}^{\mathrm{I}}(\mathrm{mm})$ & 0.00255 & 0.00251 & -1.57 \\
Hub $\Delta r_{2}^{\mathrm{II}}(\mathrm{mm})$ & 0.02295 & 0.02297 & +0.09 \\
\hline
\end{tabular}

4.3. Influence of Shape Features. An analytical solution exists for the shaft of a cylindrical (or tube) shape and the tube-shaped hub (without shape features). In the next step of the analysis, the effect of the geometry of the hub on the stress and displacement fields in the press fit joint was examined. Any change in the geometry, for which the analytical solution is derived, changes the resulting values. Then, the analytical calculation can be considered as approximate. In case the analysis deals with a bearing mounted by pressing, the inner bearing ring includes the inner race that changes the original geometry of the computational model.

A press fit joint model (Figure 5) was developed in the PTC Creo environment as an assembly of 3D geometrical models of the shaft and the inner ring bearing. Since the examined press fit joint is symmetrical in three planes, it is sufficient to use only the eighth part of the model (Figure 5) and to define symmetry conditions for entities lying in the symmetry planes.

The 6014 2RSR C3 bearing is made of bearing steel. This material is classified as a type of structural steel, although its chemical composition and, at the same time, their properties correspond more with the tool steel types. Steel types for roller bearings are hypereutectoid chromium steel types with the basic carbon content of about $1 \%$ and the chromium content of about $1.5 \%$.

Figures 6 and 7 show selected results of static analysis of radial and tangential stress distribution, along the hub thickness, that is, edge highlighted in Figure 5 of the press fit joint connecting the shaft and the inner ring of the bearing.

The effect of the changed geometry, that is, the effect of the internal bearing race groove, on the resulting stress and displacement after pressing, is shown in Figures 8-11, respectively.

Figure 11 shows the distribution of the displacement field (magnitude) of the shaft and the inner bearing ring. It can be compared with the displacement field without the shape features in Figure 4. Naturally, the shape features (the inner race groove of the bearing) change the distribution and the values of the fields. In this case, the change in field distribution is slightly modified, especially in the radius of the inner bearing rolling race.

4.4. Effect of the Interference Size and Discussion. In the next step, it is necessary to identify the size of the interference of the press fit joint and the effect of the change in the diameter displacement of the inner bearing rolling race $\Delta d_{0}^{\mathrm{II}}$ which affects the important quantity, that is, size of the bearing's radial clearance. Values of the diameter displacement of the inner bearing rolling race $\Delta d_{0}^{\mathrm{II}}$ for individual interferences of press fit $\varnothing 70 \mathrm{H} 7 / \mathrm{k} 6, \mathrm{H} 7 / \mathrm{p} 6, \mathrm{H} 7 / \mathrm{r} 6$, and $\mathrm{H} 7 / \mathrm{s} 6$ as a result of pressing are processed in Figure 12.

Figure 12 makes it evident that the size of the interference essentially influences the size of the diameter displacement of the inner bearing rolling race $\Delta d_{0}^{\mathrm{II}}$. In the analyzed press fit, $88 \%$ of the size of the interference $\delta$ is the diameter displacement of the inner bearing rolling race $\Delta d_{0}^{\mathrm{II}}$, which is a very significant proportion. Moreover, we analyzed how the effect of the interference size on the diameter of the bearing race can be reduced. The increased hub thickness reduces the percentage of interference proportion but not substantially. At the same time, it significantly increases contact pressure, which is a disadvantage.

Moreover, we have to realize that any deviation of the ideal shape of pressed contact surfaces considerably influences the shape of the bearing rolling race and thus radial clearance of bearing. The results, both analytical and numerical, consider the ideal cylindrical surface of the shaft and the inner ring. In fact, the production of cylindrical surfaces is within a certain tolerance. The accuracy of the bearing surfaces in terms of tolerances and geometric shapes is important as it is transferred to the bearing ring races. This is especially important to take into account the design of the housing, where great emphasis is placed on the accuracy of the operation. A substantial proportion of inaccuracies is transmitted to bearing ring races with thin profiles. The analyses show that any dimensional and geometric deviation of the shaft will affect the dimensional and geometric accuracy of internal race and radial clearance of the bearing, thereby substantially affecting the service life of the bearing.

Furthermore, the models did not involve temperature changes caused both by mounting and by operating conditions. The rapid heating induces thermal variations resulting in residual stresses that can introduce cracks or undesired effects to the machine parts [17-20].

\section{Conclusion}

The paper analyses the press fit joints and its dimensional parameters in order to underline the importance of the shaft 


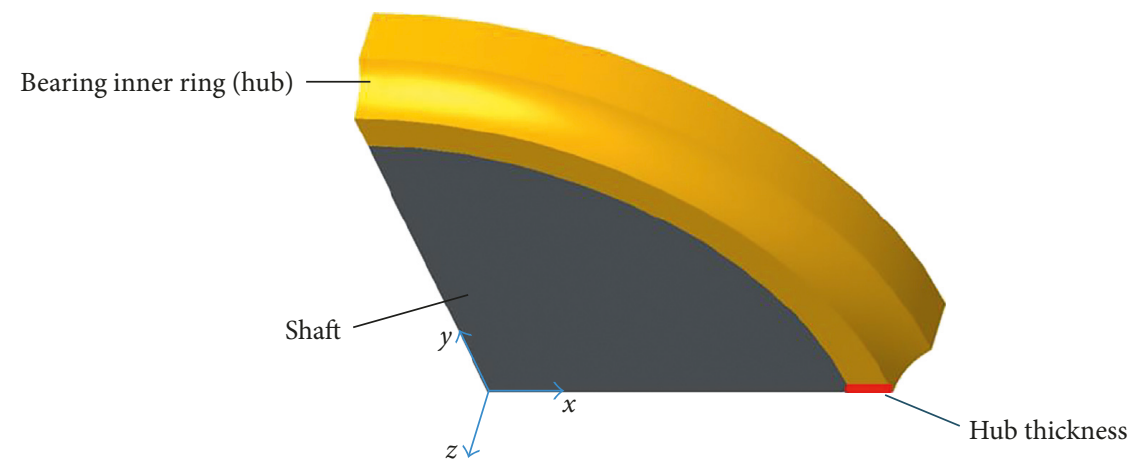

Figure 5: 3D model of press fit joint.

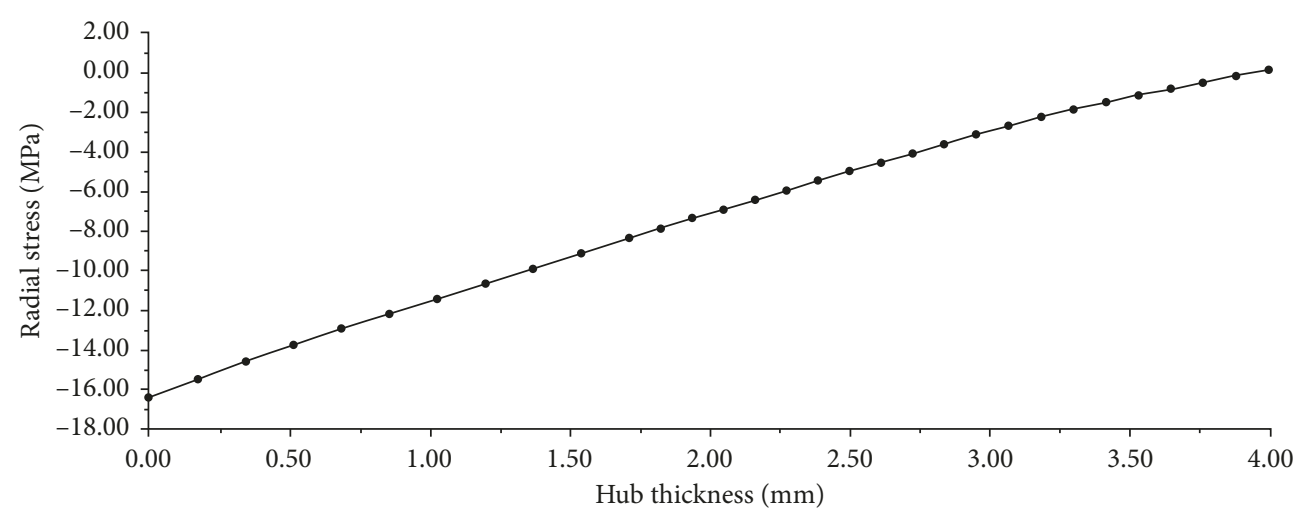

Figure 6: Radial stress of the hub.

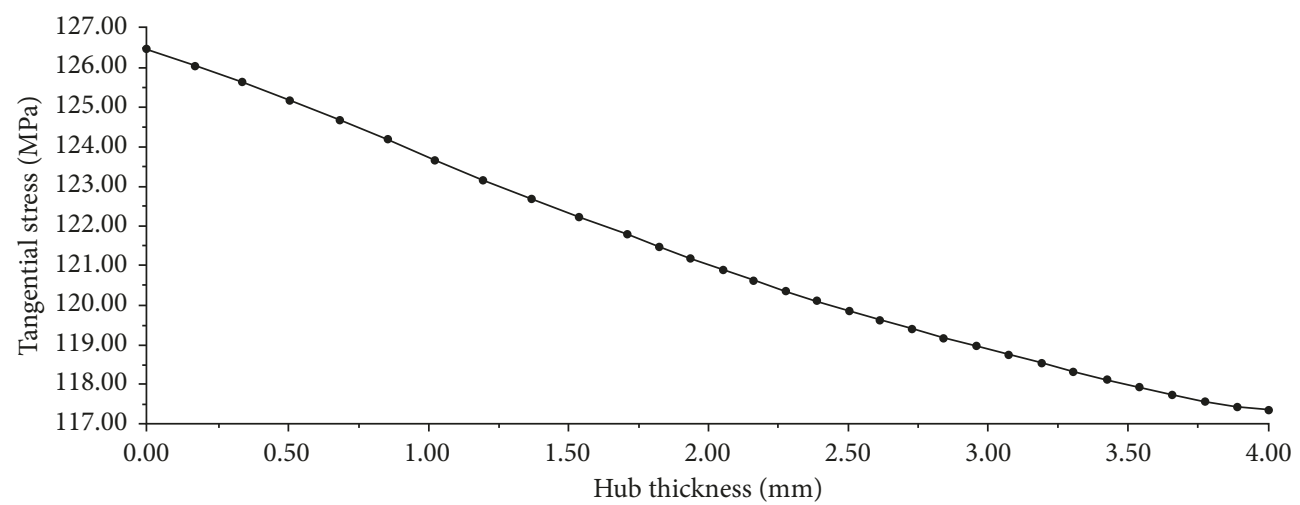

FIgURE 7: Tangential stress of the hub.

accuracy. Otherwise, the aim of the analysis and study was to determine the tangential and radial stress, the radial displacement, and the effect of the shape features and the size of the interference on the change in radii of the press fit joint connecting the bearing, namely, the 6014 2RSR C3 ball bearing and the shaft. The analytical calculation was verified by computer simulation in the PTC Creo Simulate environment. The analytical calculation and numerical experiment of radial displacement (radial and tangential stress) of the shaft and the bearing ring quantifies the portion of interference size, that is, up to $88 \%$ in our case, on inner bearing ring radial displacement after mounting the bearing onto the shaft. Thus, we can state that any inaccuracy of the shaft, both dimensional and geometric, strongly influences the dimension and shape of the bearing ring race. Then, this factor affects the functionality and life of the bearing which in turn affects the operational reliability of the entire technical system.

We confirmed that the shaft inaccuracy is the significant parameter influencing the coefficient $a$ (in (1)) along with other important parameters such as tribology conditions, radial bearing clearance, load, and so on. Naturally, the dimensional and geometrical accuracy of cylindrical surfaces (of the shaft) are obtained in the process of cutting, and thus, the cutting conditions and all effects during the cutting process influence the accuracy of the shaft and subsequently the bearing life. The dimensional and geometrical inaccuracies of the shaft highly modify the bearing life. 


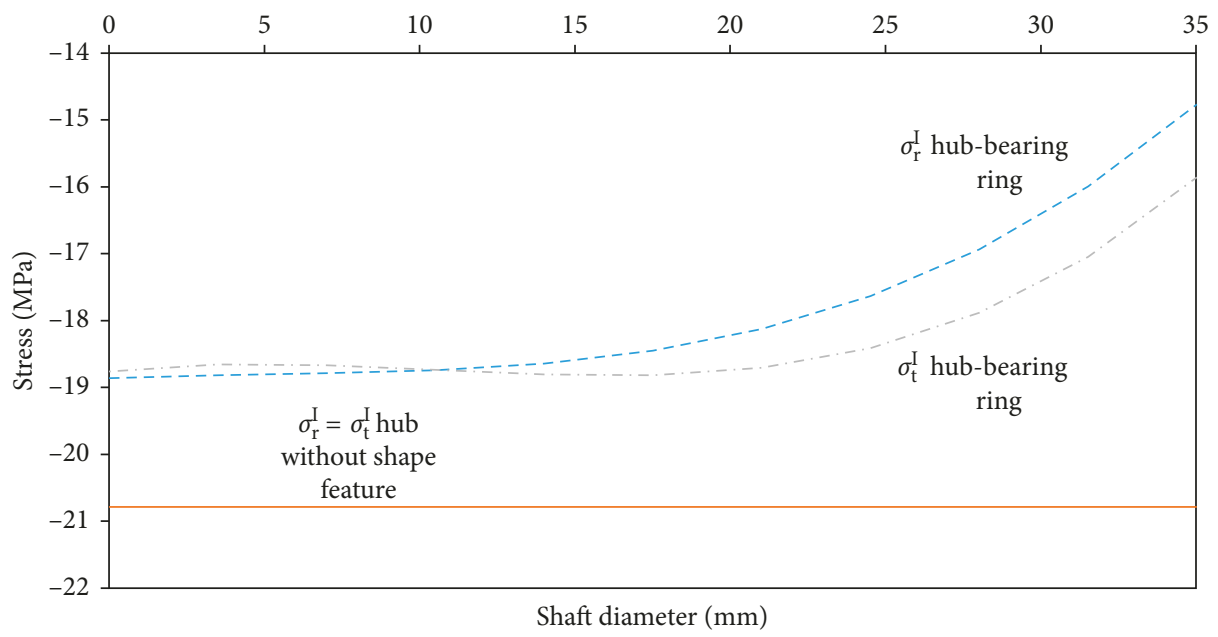

Figure 8: Radial and tangential stress (shaft) comparison.

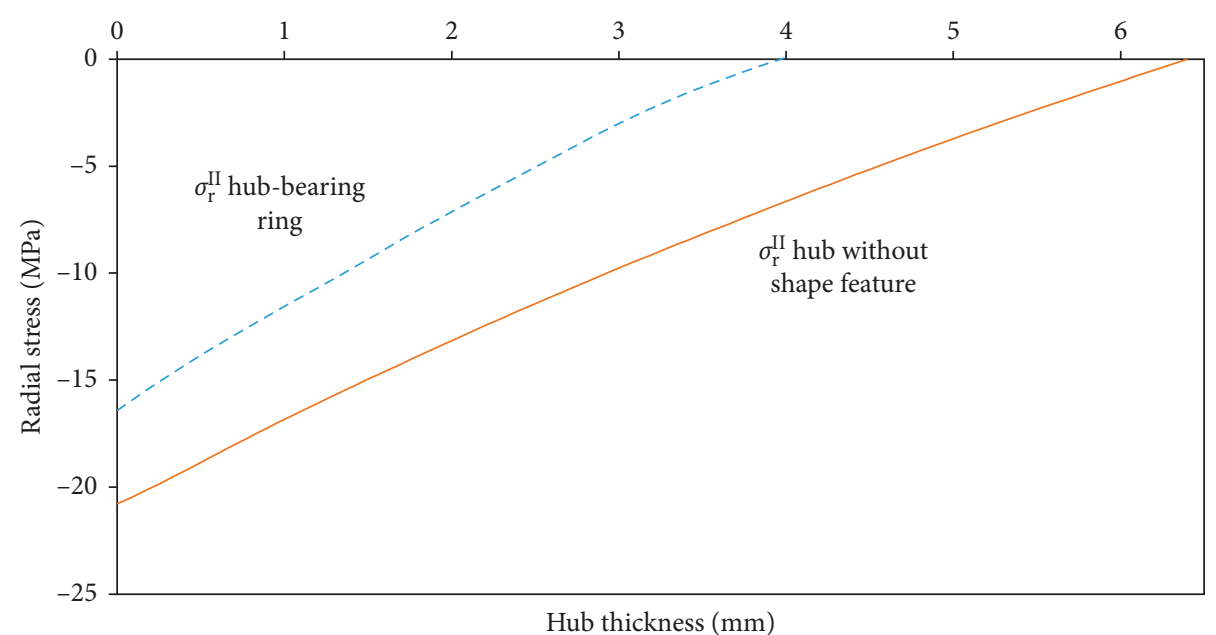

Figure 9: Radial stress (hub) comparison.

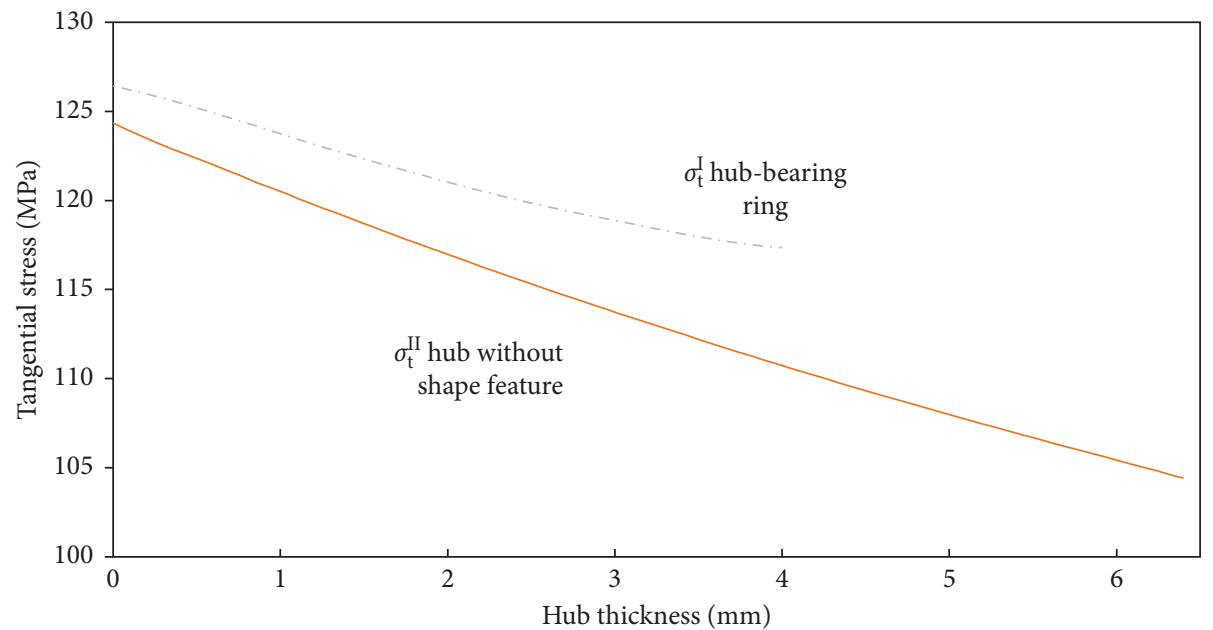

Figure 10: Tangential stress (hub) comparison. 

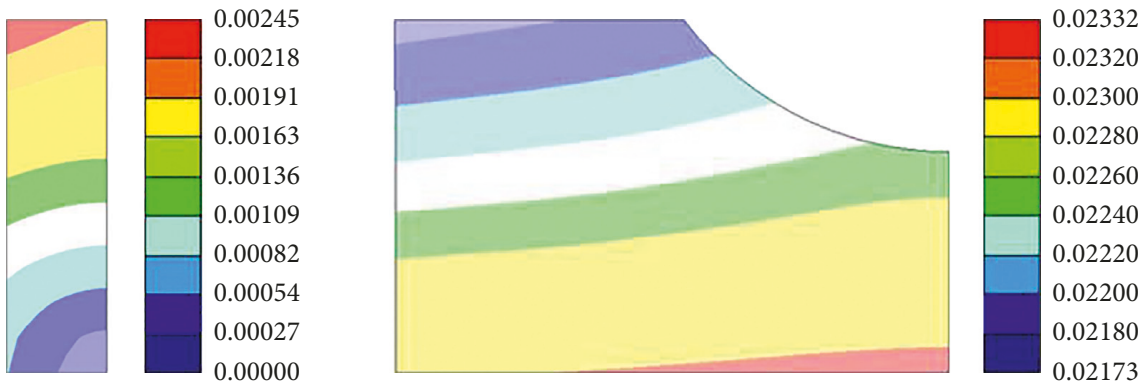

FIgURE 11: Displacement field (magnitude in millimeters)-model with shape feature.

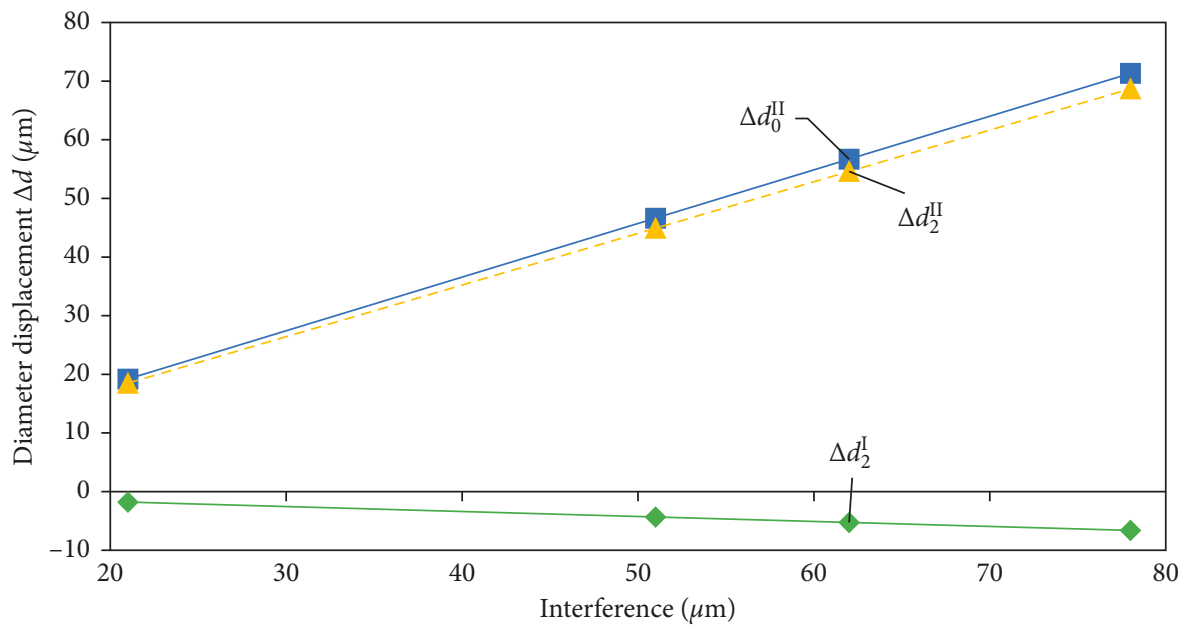

FIGURE 12: Inner bearing rolling race diameter displacement $\Delta d_{0}$ and relation to interference.

There are some users who solve their problems by buying new and/or precise (expensive) bearings. They expect the reliable operation. However, they are not satisfied as the bearing lifetime is several times even one order or two orders shorter (regarding coefficient $a$ ). The source of repeated failure can be the accuracy of shaft. The paper also contributes to the increase of professional awareness in this field.

\section{Data Availability}

The data used to support the findings of this study are available from the corresponding author upon request.

\section{Conflicts of Interest}

The authors declare that they have no conflicts of interest.

\section{Acknowledgments}

The authors thank the Ministry of education of Slovak Republic for supporting this research by the grant VEGA 1/0910/17 (Research of hybrid composite material structures in the context of their applications for improving the performance of belt gears) and KEGA 001TUKE-4/2018 (Implementation of concurrent engineering philosophy to educational tool in the field of computer aided technological preparation).

\section{References}

[1] P. Adamcik, "Systems for diagnostics of machinery," ATઐP Journal, vol. 5, pp. 20-22, 2005.

[2] P. Demec, "The mathematical models of headstock spindlebearings group inaccuracy," Acta Mechanica Slovaca, vol. 12, no. 2-A, pp. 155-158, 2008.

[3] R. W. Maruda, E. Feldshtein, S. Legutko et al., "Research on emulsion mist generation in the conditions of minimum quantity cooling lubrication (mqcl)," Tehnicki VjesnikTechnical Gazette, vol. 22, no. 5, pp. 1213-1218, 2015.

[4] J. Svetlik, J. Busa, T. Brestovic, J. Dobransky, and J. Kral, "Film thickness estimation for the oil applied to the inner surface of slim," Applied Sciences, vol. 7, no. 10, p. 977, 2017.

[5] H. Lippmann, "The effect of a temperature cycle on the stress distribution in a shrink fit," International Journal of Plasticity, vol. 8, no. 5, pp. 567-582, 1992.

[6] Y. Zhang, B. McClain, and X. D. Fang, "Design of interference fits via finite element method," International Journal of Mechanical Sciences, vol. 42, no. 9, pp. 1835-1850, 2000.

[7] G. M. Yang, J. C. Coquille, J. F. Fontaine, and M. Lambertin, "Influence of roughness on characteristics of tight interference fit of a shaft and a hub," International Journal of Solids and Structures, vol. 38, no. 42-43, pp. 7691-7701, 2001.

[8] G. S. Wang, "Stress analysis for a lug under various conditions," Journal of Strain Analysis for Engineering Design, vol. 29, no. 1, pp. 7-16, 1994.

[9] D. Croccolo, M. D. Agostinis, and N. Vincenzi, "Design of hybrid steel-composite interference fitted and adhesively 
bonded connections," International Journal of Adhesion and Adhesives, vol. 37, pp. 19-25, 2012.

[10] K. Mori, N. Bay, L. Fratini, F. Micari, and A. E. Tekkaya, "Joining by plastic deformation," CIRP Annals-Manufacturing Technology, vol. 62 , no. 2, pp. 673-694, 2013.

[11] H. Boutoutaou, M. Bouaziz, and J. F. Fontaine, "Modeling of interference fits taking form defects of the surfaces in contact into account," Materials and Design, vol. 32, no. 7, pp. 36923701, 2011.

[12] A. Bolek and J. Kochman, Parts of Machines, vol. 1, SNTL, Praha, Slovakia, 1989, ISBN 80-00193-5.

[13] S. Pavlenko, J. Halko, and J. Mascenik, Machine Parts and Mechanisms, Faculty of Manufacturing Technologies, Technical university of Kosice, Košice, Slovakia, 2013.

[14] Z. Murcinkova and J. Murcinko, "Analysis of shaft surface geometry and influence on lifetime of bearing units," Technology, vol. 5, no. 4, pp. 119-122, 2013.

[15] M. Zmindak, L. Radziszewski, Z. Pelagic, and M. Falat, "FEM/ BEM techniques for modelling of local fields in contact mechanics," Communications-Scientific Letters of the University of Zilina, vol. 17, no. 3, pp. 37-46, 2015.

[16] A. Duster, H. Broker, and E. Rank, "The p-version of the finite element method for three-dimensional curved thin walled structures," International Journal for Numerical Methods in Engineering, vol. 52, no. 7, pp. 673-703, 2001.

[17] E. Gawronska, R. Dyja, A. Grosser, and J. Winczek, "Engineering calculations for complex geometric domains," MATEC Web of Conferences, vol. 157, p. 02009, 2018.

[18] G. Krolczyk, M. Gajek, and S. Legutko, "Predicting the tool life in the dry machining of duplex stainless steel," Eksploatacja $i$ Niezawodnosc-Maintenance and Reliability, vol. 15, no. 1, pp. 62-65, 2013.

[19] G. Krolczyk, J. Krolczyk, S. Legutko, and A. Hunjet, "Effect of the disc processing technology on the vibration level of the chipper during operations process," Tehnički VjesnikTechnical Gazette, vol. 21, no. 2, pp. 447-450, 2014.

[20] R. Kumar, S. Chattopadhyaya, S. Hloch, G. Krolczyk, and S. Legutko, "Wear characteristics and defects analysis of friction stir welded joint of aluminium alloy 6061-T6," Eksploatacja i Niezawodnosc-Maintenance and Reliability, vol. 18, no. 1, pp. 128-135, 2016. 


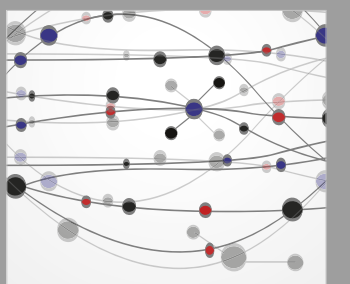

The Scientific World Journal
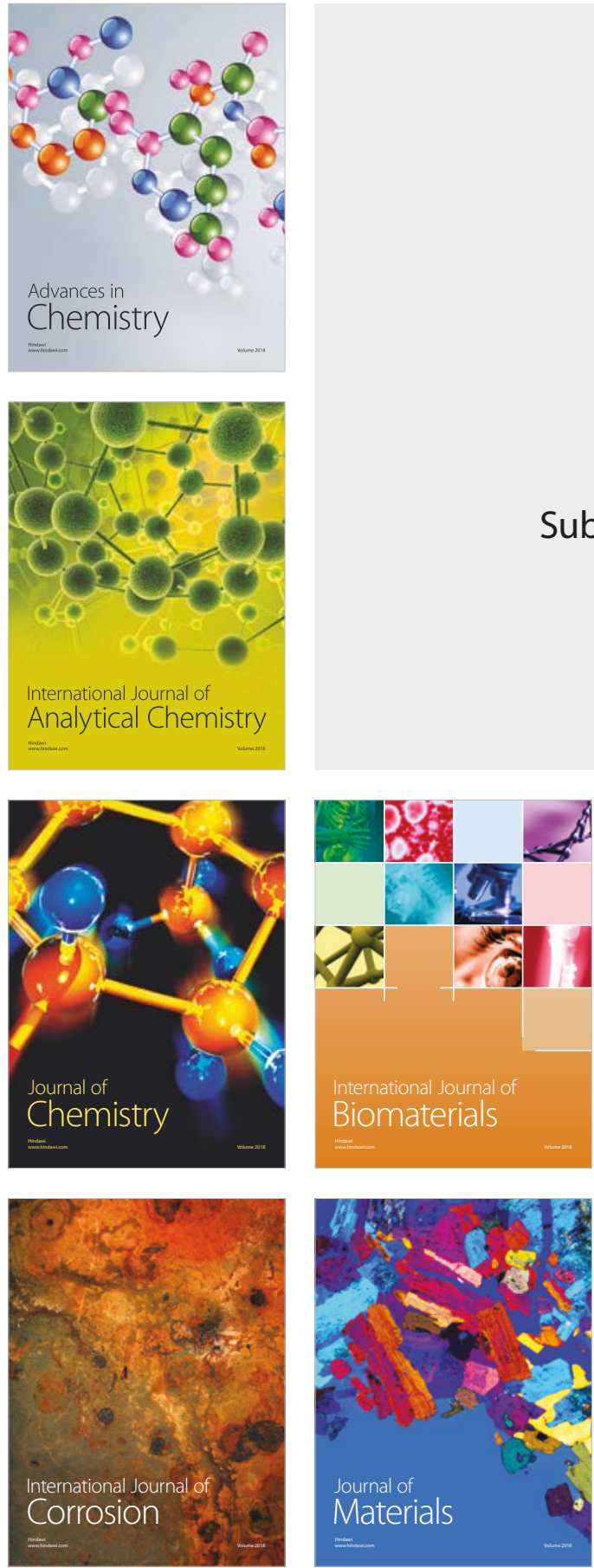

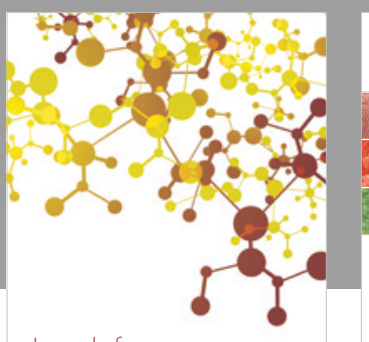

Journal of

Applied Chemistry
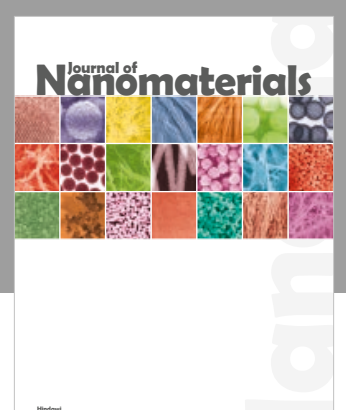

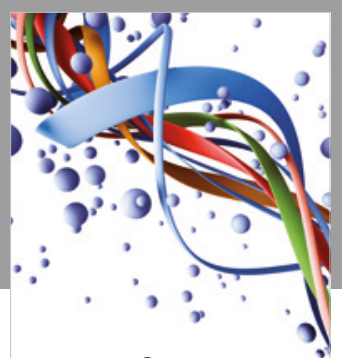

Scientifica

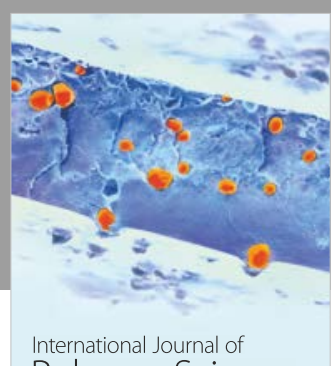

Polymer Science

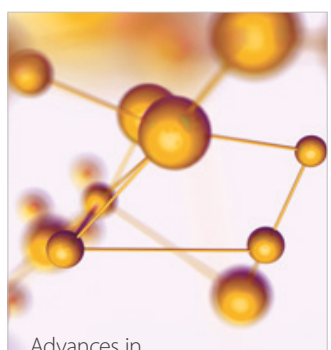

Physical Chemistry
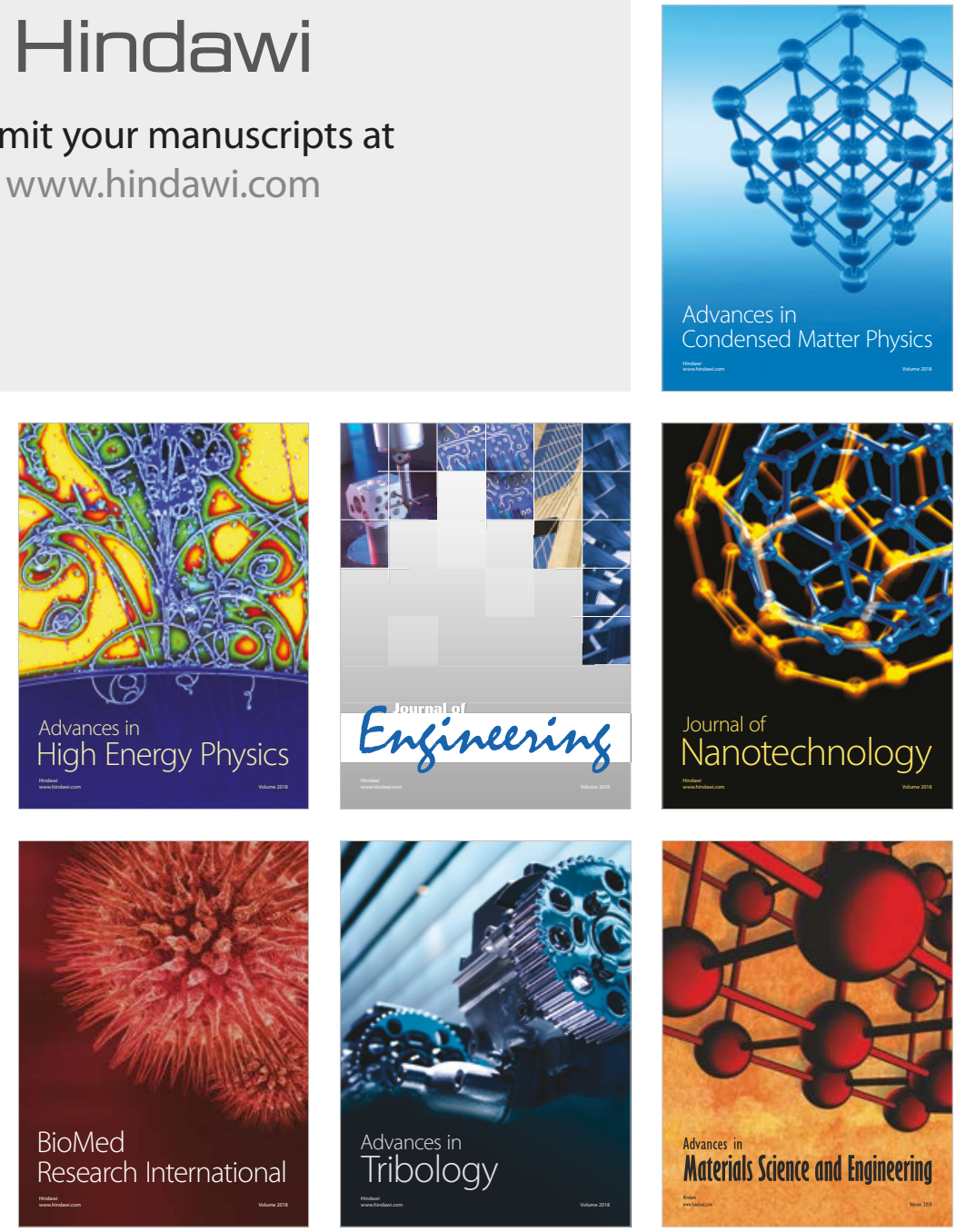